\title{
"Akuma'su Adie3" (A Hearts Desire) A Metal Mural Depicting The Psychology of Fraud
}

\author{
Abubakari Muhammed-Arafat \\ MR. ISAAC KWABENA AGYEI
}

\begin{abstract}
Fraud has over the past decade become an epidemic, impacting not only Ghana as a country or Africa as a continent but the whole world. It has proven to be a most challenging criminal act to tackle and address and hence has left many nations stunned. In Ghana Fraud accounts for about $47.7 \%$ of victimization rate in Ghana as was recorded in a 2010 report issued by the United Nations Office of Drugs and Crime (UNODC,2010). It has since then towered in severity, manifolds. In response to this increasing menace, the need arose to establish the Economic and Organized Crime Office (EOCO). This was because the "responsibility and management of fraud as well as corruption could no longer be left to police and other quasi anti-crime organizations alone. However, with the increasing sophistication of society, complex frauds and other economic crimes, EOCO despite many efforts has even become more widespread. Education and sensitization of the masses has become ever more needed in the prevention and detection of fraud. The project hence is an attempt to contribute to the education of the public regarding the severity of fraud and the need to be aware and vigilant in regards fraudulent tricks and antics through metal art. It employs various metal working methods and techniques in creating an amazing metal art which serves as an effective communicative tool for creating awareness on the psychology behind fraudulent acts in general and in particular Ghana. The production of this art piece further, exposes and widens the practical application and creativity of metal artists.
\end{abstract}

DOI: $10.7176 / \mathrm{ADS} / 89-01$

Publication date: January $31^{\text {st }} 2021$

\section{Introduction}

Akumasu Ade3 is a metal mural that seeks to depict the psychology of perpetrators and victims of fraud and how the heart and mind interrelate to influence a person's actions with regards to fraud. Fraud is an infectious canker of a criminal act that has penetrated the very fabric of our society and the institutions and facilities whose effectiveness in rendering the needed services to individuals and the society as a whole depended on the complete absence of this canker in its structure. Fraudulent acts have become so severe that these very institutions have become the reason for which individuals would have to engage in or turn a blind eye to fraud with what would appear to be a justifiable reason, fulfilling a basic need or acquiring what would be considered their right. At workplaces, people would lie or fain illness just so they could get a day off in other to attend to a personal need. Or that an individual pretends to be poor to get some benefits that are meant for the less privileged in society. Where religion is concerned we find that so-called men of God (both pastors and mallams alike) prepare some concoctions, anointing oils and many other things to swindle the congregation in believing that their problems would be solved through that," (Doulglas, 2012)

As a phenomenon, fraud is not foreign to the country of Ghana. It has thrived amongst the youth throughout generations and has existed under varying labels and forms thus the recent upsurge in mobile money fraud is only the latest in a rather aged and remaining paradigm. Notwithstanding, estimates of analysts suggest that about 50 percent of all mobile money subscribers have either been targeted or experienced one form of fraud or another (Kester \& Lartey, 2019) Formally individuals involved in fraud through the internet were known as yahoo boys and later came be known as "sakawa" boys due to their subsequent use of spiritual antiques called juju. Although this very term has gradually faded out of popularity, its essence has prevailed taking up a variety of forms throughout the ages, and mobile money fraud has in recent times taken up the limelight.

Each year, as the country becomes more and more conscious and matured technologically so does the complexity of crimes that depend on these technologies increase. According to a report issued by the Bank of Ghana in 2018 regarding incidents of fraud in the banking sector, there was a total of 2,175 fraud cases reported that year as compared to 1,418 fraud cases reported in, 2017. The total value reported for fraud or attempted fraud hence amounted to approximately GHC190.4million (Bank of Ghana, 2019)

The creation of awareness, However, and education of the masses regarding this canker of a crime also has mostly been left to the security forces tasked with the obligation of curbing the crime. Large organizations such as telecommunication companies and banks as well have carried this burden necessarily because their activities as commercial entities are directly impacted by this crime.

Each individual however has a personal responsibility to himself first and his or her society in contributing whatever they can in the protection and preservation of society. Artist in particular have the skills and toolset to educate and draw attention to challenges faced by the vulnerable in our society. In this regard, Stephanie (n.d) 
states that Artists have for many years made drawings, paintings, sculptures, and many other artefacts to challenging some assumptions, or to support causes, and to explore deep-rooted personal questions. And throughout history, art has been used for many purposes, including reinforcing religious doctrine, projecting certain political points of view, or linking religious and political power. She also stated that art would "often expand on some broad ideas and themes, whether as a support to a statement or a reaction against something."

Artists such as Suboduh Gupta choose to express their ideas primarily through metal (I Lobo you, 2017). "Gupta expresses his ideas by incorporating everyday objects that are common in India into giant installations. These would often include items such as the steel tiffin boxes, thali pans, milk pails, and even bicycles. His works would often reflect the economic changes his home town has undergone. (I Lobo you, 2017).

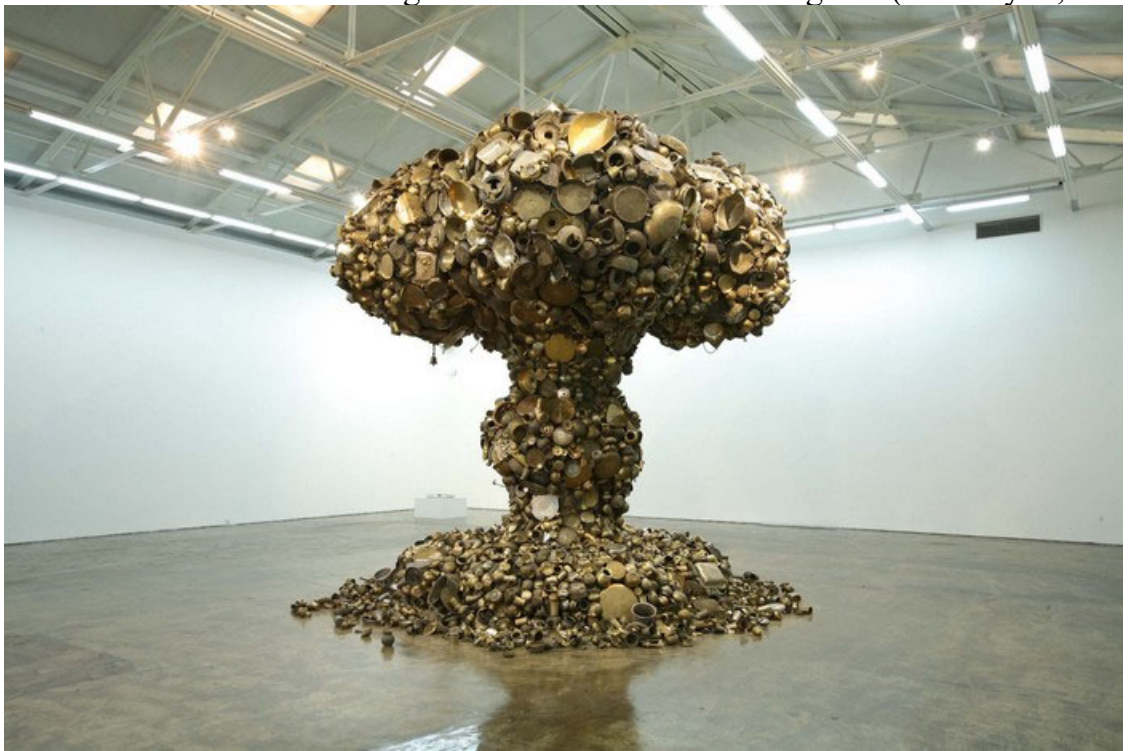

\section{Plate 1 Subodh Gupta's mushroom cloud}

In recent times conceptual art particularly has become a common medium through which people express their ideas feelings and thoughts on issues. This is partly because conceptual art by its very nature can provoke intense and sometimes extreme reactions in its audiences (Schellekens, 2019)

Ibrahim Mahama who is a renown contemporary Ghanaian artist also employs the use of conceptual art in expressing his thoughts on certain social issues in the country. Examples of his works include the "Odo Nti" and "Nkkansa" amongst many others

The objective of this study was thus to employ the use of metal art and craft to fabricate an art piece that would in part depict the mind set of both victims and perpetrators of fraud. It would also serve to communicate to the masses on the need to be vigilant against fraud.

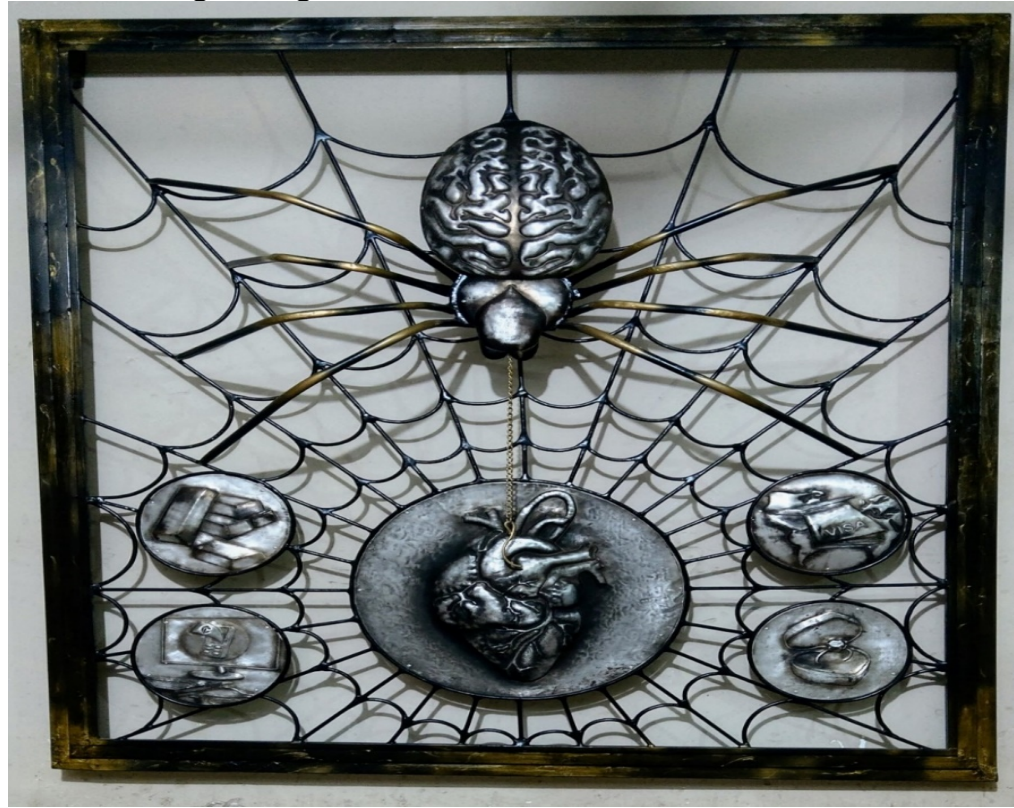

Plate 2 A hearts desire 


\section{Concept}

The phrase Akuma'su Ade3 is twi which translates to "a heart's desire". This is to indicate that a person's heart desires and needs are the driving force in a that persons potential to commit fraud or fall victim to fraud

\subsection{A spider with a human brain for its abdomen.}

The spider is representational of the Ghanaian folklore character Ananse. The name Ananse in itself also means spider. Ananse as a character is renowned for his wisdom and by virtue of which he is able to outsmart many of the other characters and figure his way out of problems. However, he would also try to take advantage of others and cheat them of their goods.

The spider and character Ananse thus were a perfect representation of the fraudster as they both share the basic characteristic of cleverness and trickery.

Furthermore, just as Ananse the character would often deceive others in other to survive, the fraudster who is often unemployed would also deceive others to survive the current economic hardship prevalent in the country.

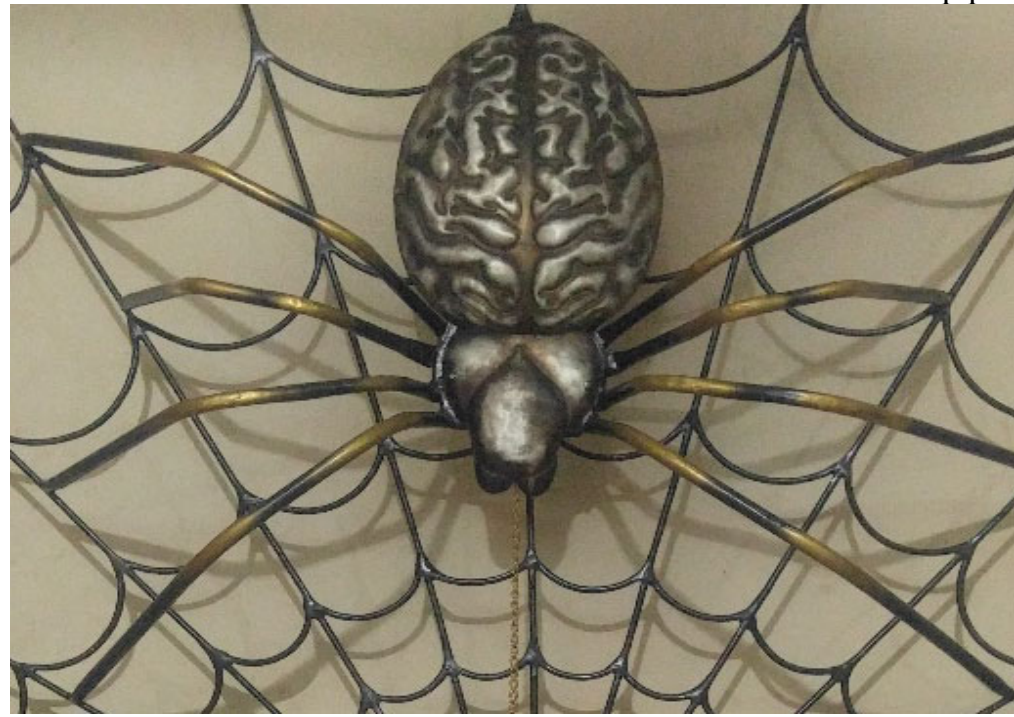

Plate 3 A close-up view of the spider

\subsection{A human heart surrounded by its desires}

The heart is representational of the victims of fraud. this is because to a very large extent, the heart plays a very significant role in a person's susceptibility to the ploys of the fraudster.

Most often people's extreme inclination to certain desires blind them to reality. They would often overlook clear cut red flags when they are engaged by these fraudsters and are thus deceived into releasing some items of value to the fraudster (Ananse). These desires, therefore become the bait by which the fraudster (Ananse) lures his/her victims to be trapped.

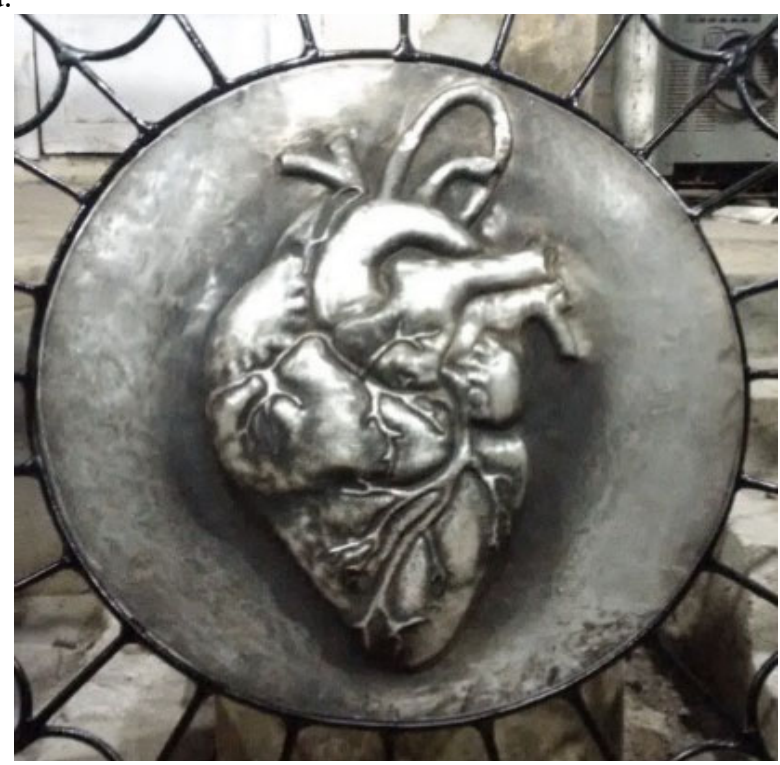

Plate 4 A close-up view of the heart 


\subsection{Ananse's web.}

This is representational of society and its tolerance to the danger fraud poses to it, as such becoming a most conducive environment for the fraudster to thrive.

\subsection{Alternate interpretation}

In this case, the spider Ananse as well as the heart and its desires relate directly to the fraudster and the underlining reason for his crimes. Amongst the many reasons a person may give, in order to justify his or her crimes they ultimately trace back to the heart and its desires, i.e. its needs and wants. Religious books of authority such as the Bible and Quran state in no uncertain terms that the heart is the seat and root for all crimes a person may commit. The bible states in Jeremiah 17 verse 9 that "The heart is hopelessly dark and deceitful, a puzzle that no one can figure out. But I, GOD, search the heart and examine the mind. It also states in Matthew 15 verse 18 to 20, "But the things that come out of the mouth come from the heart, and these things defile a person. For out of the heart come evil ideas, murder, adultery, sexual immorality, theft, false testimony, slander. These are the things that defile a person; it is not eating with unwashed hands that defiles a person."

Likewise, Islamic sources such as the Quran and the Hadith make similar assertions regarding the human heart. It states in the hadith book, Sahih al Bukhari," ...Beware! There is a piece of flesh in the body if it becomes good (reformed) the whole body becomes good but if it gets spoilt the whole body gets spoilt and that is the heart."

Thus, it is the heart that ultimately inclines towards and pushes to get all that it desires trough fraudulent acts and by whatever means possible whiles the mind tries the rationalizes and normalize these acts of evil despite a conscience.

The fraud triangle developed by Dr. Donald Cressey in 1971 establishes the bases upon which any person could become a potential fraudster he states Motivation, Rationalization, and then opportunity. Osei, Kao, and Adu comment on this stating that the motivation /pressure is what causes people to commit fraud. These pressure /motivations include financial needs and material possessions. i.e the desires of the heart

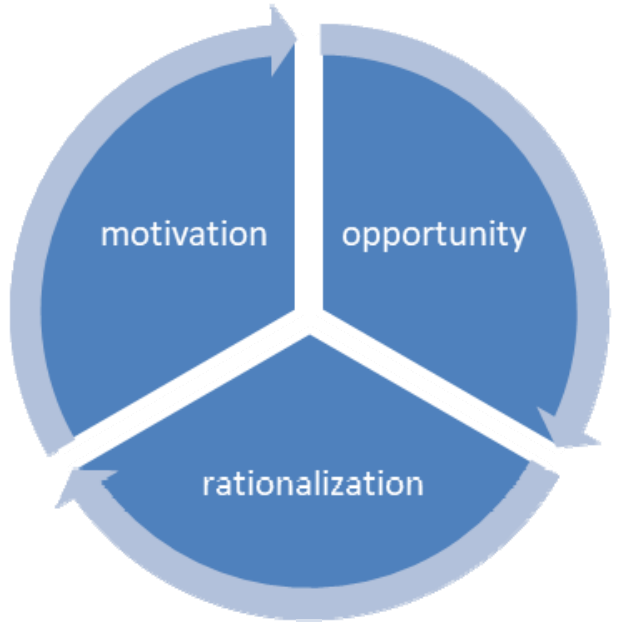

Plate 5 The fraud triangle

thus, the heart represents the motivation/pressure felt by an individual to gets to fulfill his or her needs be it financial or otherwise the spider (the brain) in this instance represents the rationalization stage of the fraudsters thought cycle. It takes a page from its original nature, as predatory. It is fed and fueled by the heart, as it schemes and considers a variety of ways to get what they want. All the while trying to justify why they have to take advantage of others and the system. Finally, the web represents the variety of opportunities provided by an unsuspecting society. 


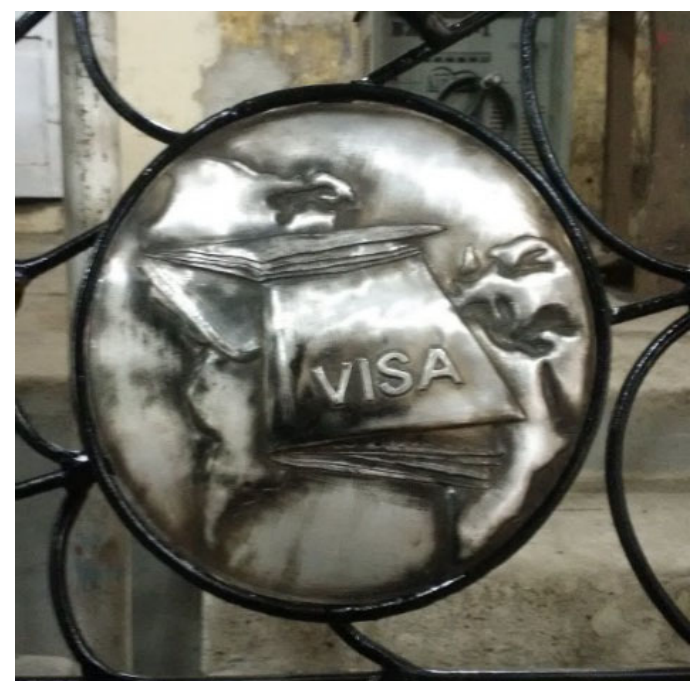

Plate 6 The desire to travel via a visa card in other to seek greener pastures in developed countries.

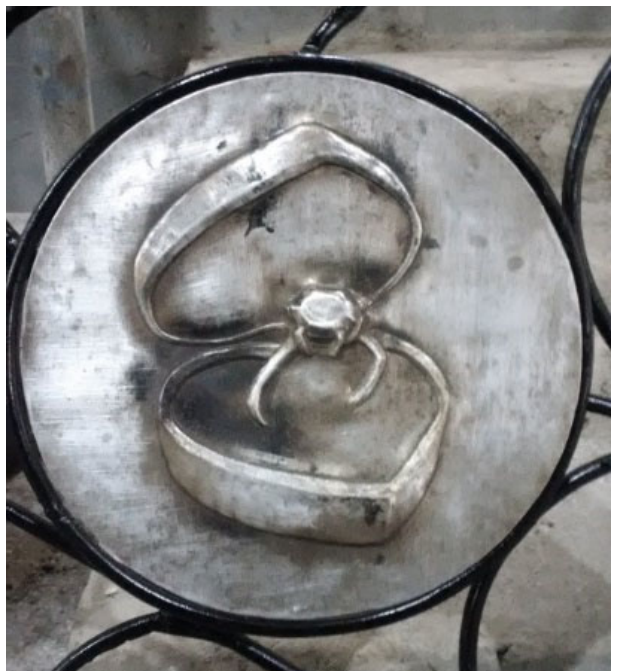

Plate 7 The desire to settle down with a loving spouse and a secures home thus making a family

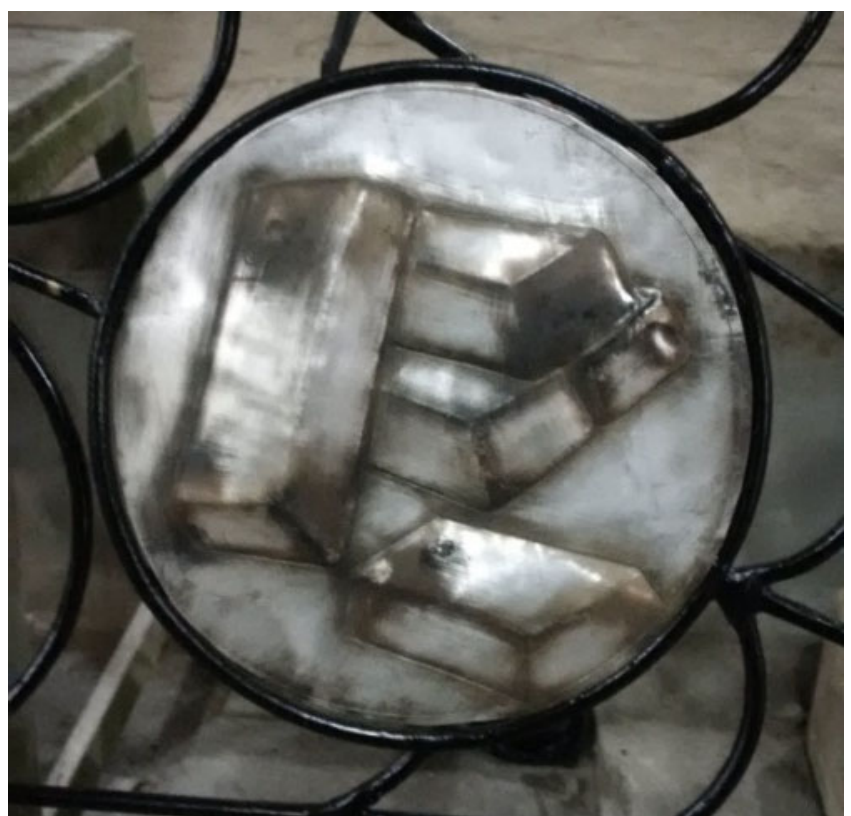

Plate 8 The desire for riches and be secured financially. 


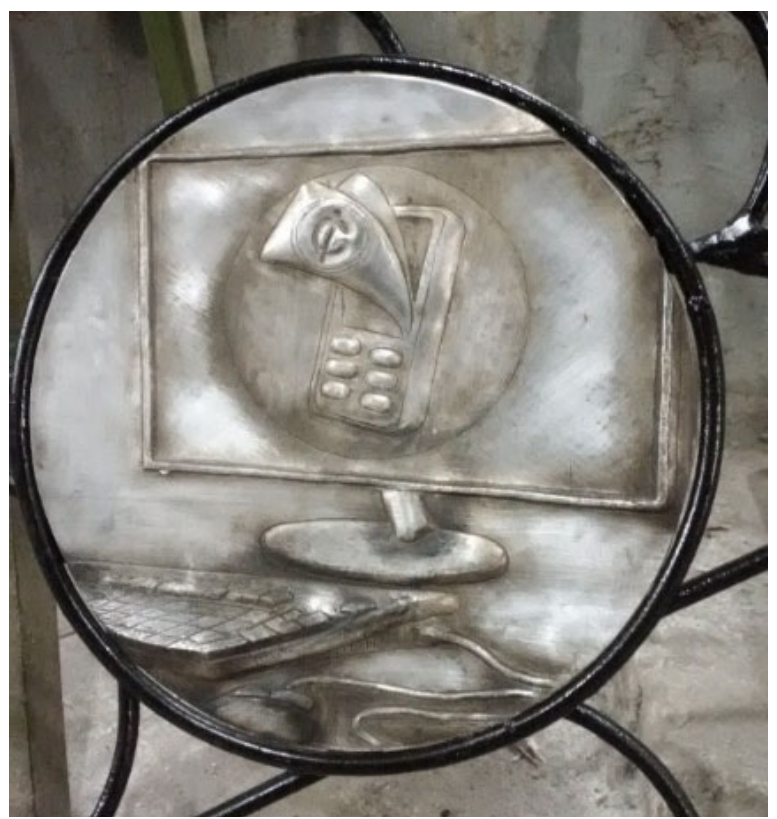

Plate 9 The desire to suddenly hit the jackpot and win some awesome prices and riches. This dream is often preached through cyber technology.

\section{Conclusion}

This study sheds light to the fact that art communicates ideas and expresses feelings, and can therefore be used as an alternative medium that helps create awareness in the fight against fraud.

The ideas and emotions of the researcher were communicated through the metallic manifestation of visual images to contribute his quota in this fight against this national menace. Many Artists past and present have embarked on similar projects in order to help develop their countries. The outcome of this project established that metal fabrication was not only limited to the creation of structural function works but could also be used to communicate verbal themes through visual images; the very essence of conceptual art.

The project communicates an idea held by the researcher through metal art. Communication thus can only be said to be complete when the message being carried across is understood by the targeted audience. Harper and Douglas (2018) confirmed that communication is the act transmitting information from one person to another by using mutually understood symbols and signs which serve as mediums through which the transmitting of information is done. Upon this bases the researcher transmitted some form of information regarding fraud trough images fabricated in metal, thus communicating to his audience via metal art. The images that were generated and used for the project were developed as a result of brainstorming, seeking the opinions of others regarding the subject fraud, and through the internet.

The outcome of this research would be very useful because concept-based metal art was fabricated to shed light upon and educate the public on some red flags and state of being that facilitate the spread of fraud in our society and the negative effects of fraud on individuals and the society as a whole.

\section{References}

Bank of Ghana. (2019). THE 2019 BANKING INDUSTRY FRAUD REPORT. Accra.

Doulglas, P. (2012, September 5). Christians should shun so-called anointing oil - Prophet Nana Tih. (GNA, Interviewer)

Kester, A. ,., \& Lartey, V. ( 2019, Augest 20). MoMo fraud threatens emerging payment technologies. Retrieved from Graphic online: https://www.graphic.com.gh/business/business-news/ghana-news-momo-fraudthreatens-emerging-payment-technologies.html

Schellekens, E. (2019). Conceptual art. Stanford Encyclopedia of Philosopy. 